\title{
Do you have something new and important to publish? Have you heard about our "Fast Track" option?
}

\author{
Friedrich Wilhelm Neukam • Peter Ward Booth
}

Received: 12 August 2012 / Accepted: 12 August 2012 /Published online: 28 August 2012

(C) Springer-Verlag 2012

We know from experience that many authors with bright ideas and good scientific papers are often frustrated by the delays in the publishing process. This is often not the fault of any one person, as the complex process of checking manuscripts, identifying appropriate referees and awaiting their deliberations can delay acceptance by months. In addition, there may be a backlog of papers and delays at the publishers. These all can add up to long delays and frustrations for the authors.

As you know, the Journal is currently going through a lot of changes and has developed as a platform for research and review articles from an international authorship. We have therefore decided to introduce the concept of "Fast Tracking" important review articles.
How will the "Fast Track" process work? If you have a new and/or important review article, send it to us and indicate your request to "Fast Track" the paper. If the editors share your enthusiasm and desire to fast track the paper, it will be fast tracked to selected referees and published within 2 months. It will be subjected to the normal peer review, and of course, some papers will be rejected for publication by the referees.

At this stage, we are going to restrict the fast track to review articles only. We hope you find this innovation helpful.
F.W. Neukam
P. Ward Booth
Editors in Chief

F. W. Neukam $(\bowtie)$

Department of Oral and Maxillofacial Surgery,

University Hospital Erlangen,

Glückstr. 11, 91054 Erlangen, Germany

e-mail: Friedrich.Neukam@uk-erlangen.de

P. Ward Booth

Department of Oral and Maxillofacial Surgery,

The Queen Victoria Hospital,

East Grinstead, West Sussex, UK 